\title{
A espacialização do tempo no memorialismo poético de Cecília Meireles, Adélia Prado e Renata Pallottini
}

\section{The spacialization of time in the poetic memorialism of Cecília Meireles, Adélia Prado and Renata Pallottini}

Angélica Soares

Resumo: Este ensaio se volta para a indissociabilidade entre tempo e espaço na memória e focaliza diferentes modos de metaforizar-se essa indissociabilidade no memorialismo poético de Cecília Meireles, Adélia Prado e Renata Pallottini. A espacialização do tempo, juntamente com a impossibilidade de sua fragmentação em momentos estanques (exclusivamente passado, presente e futuro) e de demarcação de fronteiras entre percepção e imaginação e entre lembrança e esquecimento, além de outros aspectos da memória, remetem-nos sempre para a natureza ilimitável da memória. Essas questões serão investigadas em diálogo com diferentes pensadores (Bachelard, Bergson, Deleuze, Nora, Portella) e poetas (Carlos Drummond de Andrade, Manoel de Barros e Guimarães Rosa).

Palavras-chave: Poesia brasileira. Memória. Espacialização e tridimensionalidade do tempo. Lembrança e esquecimento.

Abstract: This essay analyzes the inseparability of time and space in memory and focuses on different modes of metaphorizing this inseparability in the poetic memorialism of Cecília Meireles, Adélia Prado and Renata Pallottini. The spacialization of time along with the impossibility, on the one hand, of its fragmentation in separate moments (exclusively past, present or future) and, on the other, of the existence of boundaries between perception and imagination and between remembering and forgetting, besides other aspects of memory remind us of the boubdless nature of memory. These issues are investigated in dialogue with different thinkers such as Bachelard, Bergson, Deleuze, Nora and Portella and poets as Carlos Drummond de Andrade, Manoel de Barros e Guimarães Rosa. Keywords: Brazilian Poetry. Memory. Spacialization and three-dimensionality of time. Remembering and forgetting.

Quando Carlos Drummond de Andrade intitulou um dos seus conjuntos de poemas "Esquecer para lembrar: Boitempo III", metaforizava de forma superlativa, na referência essencial a um "boitempo", a indissociabilidade entre

\footnotetext{
"Professora Associada da Universidade Federal do Rio de Janeiro.<angelicasantossoares@gmail.com>
} 
tempo e espaço na memória, bem como nos fazia refletir sobre o fato de que só o esquecido é lembrado. E mais ainda, nos levava a incluir na memória o esquecimento, sempre mantido latente nas lembranças. Assim, a espacialização do tempo explicitava, drummondianamente, um dos aspectos da natureza ilimitável da memória que, como defendi em Transparências da memória / estórias de opressão; diálogos com a poesia brasileira contemporânea de autoria feminina, torna improcedente separar tempo e espaço e também "fragmentar o tempo em momentos estanques (exclusivamente passado, presente e futuro); demarcar fronteiras entre percepção e imaginação, realidade e ficção; dissociar lembrança e esquecimento; limitar o sujeito da recordação a uma concepção fechada e individualizadora" (SOARES, 2009, p. 14).

Este ensaio é um convite ao diálogo com poemas de Cecília Meireles, Adélia Prado e Renata Pallottini, nos quais se recria, de diferentes modos, a espacialização do tempo na memória, associada a diferentes aspectos da sua atuação sem fronteiras.

\title{
1- "Memória" e "Explicação", de Cecília Meireles.
}

\author{
A José Osório \\ MINHA FAMÍLIA anda longe, \\ com trajos de circunstância: \\ uns converteram-se em flores, \\ outros em pedra, água, líquen; \\ alguns, de tanta distância, \\ nem têm vestígios que indiquem \\ uma certa orientação. \\ Minha família anda longe, \\ - na Terra, na Lua, em Marte - \\ uns dançando pelos ares, \\ outros perdidos no chão.
}

Tão longe, a minha família! Tão dividida em pedaços! Um pedaço em cada parte... Pelas esquinas do tempo, brincam meus irmãos antigos: uns anjos, outros palhaços... 
Seus vultos de labareda rompem-se como retratos feitos em papel de seda. Vejo lábios, vejo braços, - por um momento persigo-os; de repente, os mais exatos perdem sua exatidão.

Se falo, nada responde.

Depois, tudo vira vento, e nem o meu pensamento pode compreender por onde passaram nem onde estão.

Minha família anda longe. Mas eu sei reconhecê-la: um cílio dentro do oceano, um pulso sobre uma estrela, uma ruga num caminho caída como pulseira, um joelho em cima da espuma, um movimento sozinho aparecido na poeira...

Mas tudo vai sem nenhuma noção de destino humano, de humana recordação.

Minha família anda longe. Reflete-se em minha vida, mas não acontece nada: por mais que eu esteja lembrada, ela se faz de esquecida: não há comunicação! Uns são nuvem, outros, lesma... Vejo as asas, sinto os passos de meus anjos e palhaços, numa ambígua trajetória de que sou o espelho e a história. Murmuro para mim mesma: "É tudo imaginação!".

Mas sei que tudo é memória...

(MEIRELES, 1958, p. 201-2) 
Junto à recriação do espaço/tempo no exercício memorialístico, Cecília Meireles, nesse poema, de Vaga música, nos aponta a inexistência de fronteiras entre memória e imaginação, levando-nos a reconhecer, conforme sintetizou Eduardo Portella, o caráter inventivo da memória: "É uma invenção da qual os elementos nos são fornecidos pela própria memória." (PORTELLA, 2003, p. 3). A força da memória está, mesmo, em sua inclinação para metamorfosearse e recriar-se. Manuel de Barros, em seu poema "As lições de R. Q.", integra memória e criação ao recriar a humana necessidade de "transver o mundo". Em verso antológico, ele registra o ato de transvisão, que diz melhor dessa natureza imaginativa da memória: "O olho vê, a lembrança revê, e a imaginação transvê" (BARROS, 1997, p. 75); uma vez que o que ficou para trás, se torna irresgatável em sua realidade palpável, assim como o que, na memória, já se projeta para o futuro. Transver é, pois, a própria experiência do acontecer memorante.

$\mathrm{Na}$ imaginação, incidem o alargamento do pensar, a previsão e até a vigília para a possibilidade de algo relacionado aos acontecimentos presentes e passados. Relaciona-se a imaginação, no entanto, comumente à idéia do inexistente e da irrealidade, entendidos como o não verificável empiricamente. Por outro lado (o que verdadeiramente importa), é a capacidade para criar algo que, ganhando forma, se torna possível, pois há uma força prospectiva na imaginação, pela qual temos acesso a uma presentificação do ausente, a partir do percebido. Perceber e imaginar são atos simultâneos e se impregnam mutuamente embora, constantemente, tentemos diferençá-los. O imaginar, entendido ainda, como um olhar para dentro, no qual consiste também o ato de lembrar, isto é, de guardar pela memória, permite aproximar as duas ações (olhar e guardar); visto que uma das acepções de guardar "do germânico wardôn é buscar com a vista" (FERREIRA, 1975, p. 707).

O que Cecília Meireles parece dizer-nos é tudo isso e não só. É que na ação de lembrar contamos com a imaginação, pois os fatos não se revivem, reconstroem-se, recriam-se nos descontínuos e lacunares movimentos temporais da rememoração. E a literatura é um lugar privilegiado de recriação dessa dinâmica da memória, na prática da mímesis da recordação. E assim é porque há "necessidade de basear a vida complexa numa pluralidade de durações que não têm nem o mesmo ritmo, nem a mesma solidez de encadeamento, nem o mesmo poder de continuidade" (BACHELARD, 1988, p. 7) atendendo à diversidade dos fenômenos temporais, percebida na tarefa de seriar os seus diferentes planos. A linearidade de um tempo único para todos os fenômenos os resume sempre de forma imperfeita. 
A descontinuidade temporal da recordação pontuada por Bachelard estaria ligada a um constante fluir e refluir, emergir e imergir das imagens rememoradas, em movências e deslocamentos diferentes, cada vez que se recordam; o que melhor se expressaria, por expressar-se poeticamente, nas reflexões de Riobaldo, em Grande Sertão: Veredas: "Contar é muito, muito dificultoso. Não pelos anos que já se passaram. Mas pela astúcia que têm certas coisas passadas - de fazer balancê, de se remexerem dos lugares" (ROSA, 1994, p. 121).

No poema de Cecília Meireles, o presente gramatical permite dramatizar a insuficiência dos vestígios de uma família já convertida em "pedra", "água", "líquen": sinais mobilizadores da memória, cujos traços esmaecem. A recriação poética dos "pedaços" divididos amplia a atuação da imaginação nas "imagens-lembranças" (BERGSON, 1996, p. 57-70), que ultrapassam a "humana recordação". Daí, ser possível espacializar o tempo: "Um pedaço em cada parte... / Pelas esquinas do tempo," tornando mais concretos (no sentido de cum crescere, de crescer com) os "vultos da labareda" a clarearem a mobilidade do tempo e detalhes da não exatidão, nos fragmentos longínquos.

Já em “Explicação", também de Vaga música, Cecília Meireles, quando aproxima a tristeza recordada ao sentido da esperança, não só reconstrói o passado no presente da recordação, mas instala, na reunião de espaço e tempo, a tensão com o futuro, que é própria da memória:

A Alberto de Serpa

O pensamento é triste; o amor, insuficiente;

E eu quero sempre mais do que vem nos milagres.

Deixo que a terra me sustente:

Guardo o resto para mais tarde.

Deus não fala comigo - e eu sei que me conhece.

A antigos ventos dei as lágrimas que tinha.

A estrela sobe, a estrela desce...

- espero a minha própria vinda.

(Navego pela memória

sem margens.

Alguém conta a minha história

e alguém mata os personagens.)

(MEIRELES, 1958, p. 242) 
O passado não se limita a ser recordado ("A antigos ventos dei as lágrimas que tinha"); chega ao presente ("A estrela sobe, a estrela desce...") e se abre para o sentido da possibilidade ("Espero a minha própria vinda"), ampliando-se os horizontes vivenciais, uma vez que a memória desconhece margens. O navegar, enquanto figurização do viver, ultrapassa uma noção limitada e lógico-seqüencial do tempo, organizada por conexões exclusivamente materiais (um dos modos de compreender as inclusões divinas, comuns ao universo ceciliano). Um modo de permanecer é ser lembrado após a morte, mesmo que seja em lembranças compostas também pela ausência de personagens.

A metáfora da não existência de "margens" para a memória leva-nos a fruí-la como referência a um não limite entre espaço e tempo, uma vez que por ela se desenha o curso da navegação sem bordas que, como o movimento das estrelas, está em constante deslocamento: "A estrela sobe, a estrela desce..."

Esse ir e vir da memória nos põe em contato, mais uma vez com a citada fala do roseano Riobaldo, pois as "imagens-lembranças", ao se remexerem dos lugares remexem-se no tempo, o qual se projeta memorialisticamente sempre espacializado.

\section{2- "A casa" e "Subjeto", de Adélia Prado.}

Em O coração disparado, Adélia Prado ressalta, superlativamente, a natureza afetiva e mágica da memória, quando se refere, no poema intitulado "A casa", a uma "casa de esquina" sem localização geográfica, mas reconstruída memorialisticamente:

É um chalé com alpendre,

forrado de hera.

Na sala,

tem uma gravura de Natal com neve.

Não tem lugar pra esta casa em ruas que se conhecem.

Mas afirmo que tem janelas, claridade de lâmpada atravessando o vidro, um noivo que ronda a casa

- esta que parece sombria -

e uma noiva lá dentro que sou eu. 
A espacialização do tempo no memorialismo poético de Cecília Meireles, ...

É uma casa de esquina, indestrutível.

Moro nela quando lembro, quando quero acendo o fogo,

as torneiras jorram,

eu fico esperando o noivo, na minha casa aquecida.

Não fica em bairro esta casa

infensa à demolição.

Fica num modo tristonho de certos entardeceres, quando o que um corpo deseja é outro corpo pra escavar.

Uma idéia de exílio e túnel.

(PRADO, 1987, p. 24)

A memória habita, liricamente, o poema adeliano e, como lhe é próprio, "sensível a todas as transferências (...) se enraíza no concreto, no espaço, no gesto, na imagem, no objeto" (NORA, 1993, p. 9); com o tempo memorialístico espacializando-se numa "casa de esquina", em que se mora quando se lembra. Esses enraizamentos permitem a fruição de cada detalhe, que conduz ao mergulho do sujeito nos seus mais sinceros desejos. Assim, nos é possível visualizar cenas e projeções do interior para o exterior e vive-versa, no movimento de imersão das coisas no sujeito e de emersão do que lhe vai de mais íntimo: movimentos que acabam por se inter-relacionar, "num modo tristonho de certos entardeceres". Esses motivadores involuntários da recordação mobilizam a busca erótica de "continuidade do ser" (BATAILLE, 1980, p. 17 e 91-2), que ocorreria pela penetração de um corpo em outro corpo. E lembremos, mais uma vez, com Pierre Nora, que a verdadeira experienciação memorialística se abriga também "nos saberes do corpo" (NORA, 1993, p. 14).

Em Adélia Prado, a casa é a casa, onde não há limites para a fantasia e para o desconhecido e é, ainda, o lugar do "exílio", que se quer compartilhado, pois "o que um corpo deseja é outro corpo pra escavar". E o que se espera escavar no outro é uma travessia, uma passagem, um "túnel” para a vida. Essa casa existe e é "indestrutível", porque construção de memória ("infensa à demolição").

No universo adeliano, espacializando-se em ruas que se desconhecem, situa-se a morada da memória, uma vez que ela não só penetra o inconsciente, com suas dimensões incapturáveis a nos deixarem a sensação da falta e das lacunas intraduzíveis pela palavra, mas também encaminha-nos para o mistério da vida, que assim é, pelo retrair-se próprio da existência que, ao se revelar, velando-se, permite que se ritualize o visível no invisível. E porque 
a memória resguarda o silêncio (o vigor memorante), o que se edifica por ela não se esgota e não se destrói. Possuidora de uma força incalculável, sustenta uma permanência que não se deixa controlar; como diria Nora, "susceptível de longas latências e de repentinas revitalizações" (NORA, 1993, p. 9). A "casa aquecida" de Adélia Prado nos oferece uma vivência instigantemente poética, iluminada pela energia revitalizante da memória, com a simbólica "claridade de lâmpada atravessando o vidro", desnudando transparências insuspeitadas.

A consciência adeliana da memória como promotora de um modo fugidio de experienciação, que é inalienável da existência humana, se explicita também em $O$ coração disparado, no poema, cujo título "Subjeto" preserva a idéia do que se lança de baixo, dos recônditos territórios do inconsciente para a consciência: em associações espácio-temporais de objetos, lugares, sensações etc. que o recordador parece querer conservar tais quais foram vividas e / ou imaginadas e, ao mesmo tempo, quer transmiti-las com palavras, embora saiba que estas as deformam, por conformá-las sempre diferentemente e insuficientemente:

O cheiro da flor de abóbora, a massa de seu pólen, para mim, como óvulo de coelhas.

- Vinde zangões, machos tolos, picar a fina parede que mal segura a vida, tanto ela quer viver.

Ainda que não vos houvesse eu fecundaria essas flores com meu nariz proletário.

- Ora, direis, um lírio ignóbil.

Pois vos digo que a reproduzo em ouro sobre meu vestido de núpcias, meu vestido de noite. Dentro do quarto escuro, ou na rua sem lâmpadas, de cidade ou memória, um sol.

Como pequenas luzes esplêndidas.

(PRADO, 1987, p. 27)

Em "Subjeto", como em toda a escrita poematizada pela memória, o verso, cortando as frases, parece querer expor os cortes entre o vivido ou o possivelmente vivido e o narrado, de forma predominantemente lírica, abrindo-se sulcos transversais para a passagem do imaginário e, com ele, o trânsito para o sentido simbólico das imagens relembradas que, acionadas pela 
imaginação, reúnem, muitas vezes, o que nos poderia parecer sem nenhuma relação aparente, não fosse o significado emocional e existencial que têm elas para o recordador.

A recordação do que estaria subjacente na memória caminha, direcionada pelas forças geradoras das sensações, da "flor de abóbora" com o seu "pólen" para a "fecundação", as "núpcias", o "quarto escuro" ou a "rua sem lâmpadas", que se iluminam pelo "ouro" da "flor de abóbora", já agora bordada no "vestido de noite", a resplandecer como um sol, conjugando todas as "pequenas luzes esplêndidas" e aí o valor esplendoroso do que poderia aparecer, na dicção intertextual olavobilaqueana (BILAC, 1977, p. 53) como um "lírio ignóbil" é o que se preserva. E, se essa "rua" é "de cidade ou de memória" não importa. O que importa para a recordadora é a natureza solar do seu desejo simples e "proletário" de viver e de produzir vida.

\section{3- "Se ainda é tempo de lembrar, se ainda é tempo" e "História", de Renata Pallottini}

As disponibilidades da obra poética de Renata Pallottini para a metamemória nos fazem vivenciar a indissociabilidade entre tempo e espaço, a promover no recordador o encontro da precisão no impreciso, da solidez no fluido, da claridade no que já não se vê. E a natureza do tempo acaba por ser espacial, um lugar do passado que se faz presente, ganhando forma e antecipando o futuro, basta que seja "tempo de lembrar". Vejamos:

Se ainda é tempo de lembrar, se ainda é tempo

força é guardar espaço na memória

para esse tempo antigo

até que espaço e tempo se penetrem

e uma rua qualquer se torne

aquela rua

e um inverno qualquer aquele frio,

até que árvores verdes se transformem

na árvore esperando a primavera

e eu - que importo - caminhe como outrora. 
Se é tempo ainda de esperar, se é tempo ainda

força é guardar no corpo um frêmito, e nos olhos

um brilho sempre casto, algum lampejo

para a hora do encontro desse tempo.

Terei então memória limpa, e a face

resguardada de tudo há de sorrir fitando os ventos.

Terei claros de neve e sóis

no pensamento.

E o que foi me virá como um presente

e eu o receberei como o quis,

como sempre.

Assim é que há de ser e será

se ainda é tempo.

(PALLOTTINI, 1995, 187-8)

O "tempo de lembrar" se une sempre a outro, nos horizontes do humano: o "tempo de esperar". E, pallottianamente, descobrimos que lembrar e esperar também não se dissociam e não se limitam, nem no corpo nem no espírito, porque acabam por ser da ordem do desejo, mantenedor da vida.

Impossível é, pois, medir o tempo, ou melhor, mensurar os espaços entre rememoração e esquecimento, guardados na memória como territórios indemarcáveis.

O tempo / espaço da memória, então, configura-se como "um presente": uma presença e uma dádiva recebidas "como sempre". E a forma condicional poematizada no "se ainda é tempo" parece presentear-nos com a certeza de que em qualquer tempo é possível sentir "aquele frio", "um frêmito", "um brilho" e "algum lampejo" do que "há de ser e será".

O poema nos transporta, essencialmente, para o fragmento 18 de Heráclito, por abrigar ele uma verdade, desde sempre destinada ao homem pela inseparabilidade de tempo e espaço: "Se não se espera, não se encontra o inesperado, sendo sem caminho de encontro nem vias de acesso" (HERÁCLITO, 1980, p. 57). Pallottini nos fala de caminhadas e encontros que, como em Heráclito, se mantêm em mistério e, assim sendo, revigoram o caminhar, na experienciação da espera, que se insere no movimento das transformações e nos cruzamentos espácio-temporais de "inverno" e "primavera", de querer e 
receber - transformações que indiciam o modo humano de espacializar-se: temporalizando-se tridimensionalmente.

O reconhecimento poético dessa dinâmica da existência se faz também pela reunião de poesia e pensamento, que caracteriza o estilo pallottiniano, em "HISTÓRIA":

\author{
É uma estranha memória \\ a que une esta música \\ a tão velhas histórias. \\ Mais que histórias, ambientes, \\ ar frio e fino de bairro, \\ mas bairro de antigamente.
}
Tudo vago no tempo num tempo de passado, com esquinas e campos e meninos deitados a dormir (a dormir?), com meninos perdidos hoje adultos e graves, incapazes de amor do quanto eram capazes.
É uma estranha memória, uma dor implacável.
Na esquina desse tempo que vida eu me preparava? Esta vida, com certeza. Só que inda a não carregava.

(PALLOTTINI, 1995, p. 180-1)

Ao voltar-se para os signos proustianos da Recherche, Gilles Deleuze (1987) alerta para o sentido do aprendizado temporal, efetuado por intervenção da memória, que se direciona para o futuro. E, longe de ser um saber abstrato, esse aprendizado exige signos a serem decifrados, interpretados (acrescentaria eu, em seu revelar ocultando) configurando-se, simultaneamente, a unidade e a pluralidade dos acontecimentos rememorados, na configuração de mundo, para a qual confluem diferentes mundos de signos: os mundanos, os do amor e os das impressões ou das qualidades sensíveis. 
Em "HISTÓRIA", ao unir-se a impressão sentida de "esta música" a "tão velhas histórias", pela "música" presentifica-se o passado, como se a qualidade sensível, experimentada pelo sujeito, "envolvesse, mantivesse aprisionada a alma de um objeto diferente daquele que ela agora designa" (DELEUZE, 1987, p. 11), daí sentir-se afetado por uma "estranha memória"; dando a sensação, tal qual em Proust, de "tempo redescoberto" (DELEUZE, 1987, p. 12). A qualidade sensível do signo "música" se materializa de forma que todos os outros ("ar frio e fino de bairro", "esquinas e campos", "meninos") surgem não "como produto de uma associação de idéias, mas em pessoa e em essência" (DELEUZE, 1987, p. 13), de modo semelhante às referências deleuzianas à Recherche. De uma sensação de "tudo vago no tempo / num tempo de passado", que é também o "hoje" de "meninos perdidos", agora "adultos e graves / incapazes de amor / de quanto eram capazes", brota uma "dor implacável", que é presente, mas que já se "preparava". Essas interseções se vivenciam e se recriam no poema, justamente, pelo reconhecimento da interseção de tempo e espaço: "Na esquina desse tempo / que vida eu me preparava? / Esta vida, com certeza. / Só que inda a não carregava". Isto porque os signos sensíveis da memória ultrapassam sempre os significados de sua materialidade e abrem passagem para os signos da arte, a permitirem identificar nas "esquinas" do tempo, ângulos insuspeitados e a presença de ausências, em latências prontas a se manifestarem e a serem recordadas.

São às lições deleuzianas que a "HISTÓRIA" de Pallottini, em última instância, nos remete; assim como nos dirigem todas as imagens recriadas artisticamente pelo vigor da memória, porque:

(...) o mundo revelado da Arte reage sobre todos os outros, principalmente sobre os signos sensíveis; ele os integra, dá-lhes o colorido de um sentido estético, e penetra no que eles tinham ainda de opaco. Compreendemos então que os signos sensíveis $j a ́$ remetiam a uma essência ideal que se encarnava no seu sentido material. Mas sem a Arte nunca poderíamos compreendê-los, nem ultrapassar o nível de interpretação que correspondia à análise da madeleine. É por esta razão que todos os signos convergem para a arte; todos os aprendizados pelas mais diversas vias, são aprendizados inconscientes da própria arte. No nível mais profundo, o essencial está nos signos da arte. (DELEUZE, 1987, p. 14) 


\section{Referências}

ANDRADE, Carlos Drummond de. Esquecer para lembrar: Boitempo III. Rio de Janeiro: José Olympio, 1979.

BACHELARD, Gaston. A dialética da duração. Trad. Marcelo Coelho. São Paulo: Ática, 1988.

BARROS, Manoel de. Livro sobre nada. 3. ed. Rio de Janeiro: Record, 1997.

BATAILLE, Georges. O erotismo. 2. ed. Trad. João Bénard da Costa. Lisboa: Moraes, 1980.

BERGSON, Henri. Matéria e Memória: ensaio sobre a relação do corpo com o espírito. Trad. Paulo Neves da Silva. São Paulo: Martins Fontes, 1996.

BILAC, Olavo. "Ora (direis) ouvir estrelas! Certo” In: . Poesias. 29.ed. Rio de Janeiro: Civilização Brasileira, 1977. p.53.

DELEUZE, Gilles. Proust e os signos. Trad. Antonio Carlos Piquet; Roberto Machado. Rio de Janeiro: Forense Universitária, 1987.

FERREIRA, Aurélio Buarque de Hollanda. Novo dicionário da língua portuguesa. Rio de Janeiro: Nova Fronteira, 1975.

HERÁCLITO. Fragmentos: origem do pensamento. Trad., introdução e notas de Emmanuel Carneiro Leão. Rio de Janeiro: Tempo Brasileiro, 1980.

MEIRELES, Cecília. Obra poética. Rio de Janeiro, Nova Aguilar, 1958.

NORA, Pierre. Entre memória e história: a problemática dos lugares. Trad. Yara Aun Khoury. Projeto história, São Paulo: 10, 1993. p.7-28.

PRADO, Adélia. O coração disparado. 4.ed. Rio de Janeiro: Guanabara, 1987.

PALLOTTINI, Renata. Obra poética. São Paulo: Hucitec, 1995.

PORTELLA, Eduardo. Paradoxes de la mémoire. Diogène, Paris, v.201, p.3-4, 2003.

ROSA, João Guimarães. Ficção completa. Rio de Janeiro: Nova Aguilar, 1994.

SOARES, Angélica. Transparências da memória / estórias de opressão: diálogos com a poesia brasileira contemporânea de autoria feminina. Florianópolis: Mulheres, 2009.

Recebido para publicação em 12 set. 2011. Aceito para publicação em 10 out. 2011. 